\title{
Development of a new method to preserve caprine cauda epididymal spermatozoa in-situ at $-10^{\circ} \mathrm{C}$ with electrolyte free medium
}

\author{
Uttam Datta • M. Chandra Sekar • \\ Manik Lal Hembram • Raju Dasgupta
}

Received: 29 June 2009 / Accepted: 31 August 2009 / Published online: 17 September 2009

(C) Springer Science + Business Media, LLC 2009

\begin{abstract}
Purpose In-situ preservation of cauda epididymal spermatozoa at $-10^{\circ} \mathrm{C}$ with electrolyte free media for obtaining maximum functional gametes than preservation at $5^{\circ} \mathrm{C}$.

Methods Electrolyte free media prepared with soybean lecithin-glycerol, Coenzyme Q10 - glycerol and soybean lecithin - Coenzyme Q10 - glycerol were inoculated separately into ligated cauda epididymides, equilibrated $2 \mathrm{~h}$ at $5^{\circ} \mathrm{C}$, wrapped with aluminium foil and freezed at $-10^{\circ} \mathrm{C}$. Spermatozoan characters were evaluated 7 and 21 days after thawing at $38.5^{\circ} \mathrm{C}$ in a water bath for $5 \mathrm{~min}$.

Results Spermatozoan characteristics were diminished gradually and significantly $(p<0.001, p<0.05)$ between the media and observation days. Soybean lecithin-CoenzymeQ10glycerol effectively protected spermatozoa against cold shock where spermatozoan progressive motility, viability,
\end{abstract}

Capsule In this method spermatozoa remaining within ligated cauda epididymides were treated with electrolyte free media and freezed at $-10^{\circ} \mathrm{C}$ and were assessed after thawing.

U. Datta $(\bowtie) \cdot$ M. Chandra Sekar $\cdot$ M. L. Hembram Department of Veterinary Gynaecology \& Obstetrics, Faculty of Veterinary and Animal Sciences West Bengal University of ANIMAL and Fishery Sciences,

37and 68, Kshudiram Bose Sarani, Belgachia,

Kolkata 700037 West Bengal, India

e-mail: uttamdtt@yahoo.com

R. Dasgupta

Department of Animal Genetics and Breeding, Faculty of Veterinary and Animal Sciences West Bengal

University of ANIMAL and Fishery Sciences,

37 and 68, Kshudiram Bose Sarani, Belgachia,

Kolkata 700037 West Bengal, India

e-mail: wbuafs@wb.nic.in hypo-osmotic swelling positivity were $30.2 \pm 0.62 ; 45.2 \pm$ 0.82 and $41.6 \pm 0.79$ percent respectively on day 21 .

Conclusion This method can be adopted in field conditions for transportation of frozen epididymides and re-utilization of maximum functional gametes to conserve valuable animals after postmortem / slaughter.

Keywords Coenzyme Q10 - Electrolyte free medium . Epididymal spermatozoa $\cdot$ Freezing $\cdot$ Hypo-osmotic swelling test

\section{Introduction}

Interest in using epididymal sperm from domestic and nondomestic species is increasing because of the inherent value of individuals who die before making a contribution to the genetics of their own population, to reduce the risk of increase in inbreeding co-efficient in captive animal populations, and to insure the preservation of genetic variability of endangered species within closed captive populations [1]. Moreover, the ability to use the epididymal sperm from males, culled in zoos, parks, sanctuaries or in the wild could preserve their "wild DNA" for introduction into captive populations. However, due to unpredictability of death and often the remoteness of valuable / exotic males, or animals kept in captive condition at the time of death, harvesting and cryopreservation of epididymal sperm in a timely manner are not often feasible. Hence, to maintain the quality of slaughtered / postmortem collected epididymal sperm, preservation methods need to be developed through Artificial Reproductive Technologies (ART) to replenish the gene pool of wild and captive animals that can further increase the utility of sperm. 
Many experiments have evaluated the efficacy of epididymal sperm collection from various domesticated and wild animals at different timed intervals after post mortem, and their preservation at 4 to $5^{\circ} \mathrm{C}$ or at $-196^{\circ} \mathrm{C}$ showed a substantial loss in the sperm characteristics before and after preservation [1-8]. Six hours after postmortem collection, caprine spermatozoa within the cauda epididymides have been reported to preserve successfully for $96 \mathrm{~h}$ at $4^{\circ} \mathrm{C}$ and were able to fertilize ova [9]. Canine epididymal spermatozoa also collected six hours after postmortem were preserved for up to 8 days at $5^{\circ} \mathrm{C}$ where spermatozoan progressive motility and membrane integrity were $50 \%$ and $80 \%$ respectively [10].

Pregnancies and live births from ART using fresh, cooled or cryopreserved epididymal sperm have been performed successfully in various domesticated and wild animals including human [3, 11-22].

Though advances have been made through ARTs, preservation of valuable gametes from endangered/ exotic species requires further research. Importantly, research should be carried out using related domestic species to develop/ determine the basic protocols prior to extending the techniques which can be modified to best fit the valuable species being studied. Moreover, to prevent maximum loss of valuable gametes and to recover maximum functional gametes for a considerable long period from postmortem animals, new strategies for preservation of epididymal sperm in field condition could be thought off instead of preservation at 4 to $5^{\circ} \mathrm{C}$.

Considering the importance of biodiversity and of domestic species genetic resources preservation, this study suggests a new method for epididymal sperm preservation aiming to - (i) formulate the electrolyte free (EF) media using soybean-lecithin (SL) and Coenzyme Q10 (CoQ10) and to evaluate their efficacy on Jamunapari buck spermatozoa remaining in-situ in the ligated cauda epididymides after storage at $-10^{\circ} \mathrm{C}$. (ii) Maximize the recovery of functional gametes and their transport after a long period of freezing and (iii) establish of an effective protection protocol of valuable genotype of exotic / endangered species after slaughter / postmortem especially in field condition or in less facilitated laboratories for transportation and re-utilization of freezed gametes for cryobanking and for use in ART.

\section{Materials and methods}

Materials

Chemicals and reagents were purchased from E. Merck (India) Limited, Mumbai 400048, India and SISCO Research Laboratories PVT. LTD., Mumbai-400099, India.
Preparation of cauda epididymides

Normal testes $(n=80)$ from adult and healthy Jamunapari bucks were collected from local abattoir immediately after slaughter. The organs were shifted to laboratory in Styrofoam container at $5^{\circ} \mathrm{C}$ in a plastic bag containing normal saline solution (NSS). Tunica albugenia were removed from the testes. Fat-pad, blood vessels, adipose and connective tissues were cleaned carefully, and washed thoroughly with cold NSS. As per anatomical positions ligatures were placed unilaterally at the cauda epididymides (i.e. posterior region of the corpus epididymis and anterior region of the vasdeferens respectively). All the testes attached with ligated epididymides were kept at $5^{\circ} \mathrm{C}$ in a refrigerator for $10 \mathrm{~min}$.

Preparation of the electrolyte free (EF) media

Before preparation of the EF media, experiments were conducted to select optimum concentration of fructose, glycerol (G), soybean lecithin (SL), coenzyme Q10 (CoQ10) and antibiotic used on the basis of spermatozoan progressive motility and hypo-osmotic swelling positivity.

Soybean lecithin-glycerol (SLG): Fructose $1.5 \mathrm{~g}$, SL $40 \mathrm{mg}$, Glycerol $6.5 \mathrm{ml}$, Gentamycin $50 \mathrm{mg}$, bidistilled water upto $100 \mathrm{ml}$.

CoQ10-glycerol (CoQ10G): Fructose $1.5 \mathrm{~g}$, CoQ10 $30 \mathrm{mg}$, Glycerol $6.5 \mathrm{ml}$, Gentamycin $50 \mathrm{mg}$, bidistilled water upto $100 \mathrm{ml}$.

Soybean lecithin-CoQ10-glycerol (SLCoQ10G): Fructose $1.5 \mathrm{~g}$, SL $40 \mathrm{mg}$, CoQ10 $30 \mathrm{mg}$, Glycerol $6.5 \mathrm{ml}$, Gentamycin $50 \mathrm{mg}$, bidistilled water upto $100 \mathrm{ml}$.

Three media were prepared into separate glass beakers and were allowed to stir by magnetic stirrer for $1 \mathrm{~h}$ at $5^{\circ} \mathrm{C}$. Media were passed through Millipore filters $(0.25 \mu \mathrm{m})$ separately and were kept into sterilized amber coloured coded glass bottles at $5^{\circ} \mathrm{C}$. The $\mathrm{p}^{\mathrm{H}}$ of the media was adjusted to 6.8. The prepared media were used within 7 days.

Inoculation, equilibration and freezing procedures

Two $\mathrm{ml}$ precooled individual EF medium was inoculated very slowly into each ligated cauda epididymis separately ( $n=10$ for each medium and for observation days) with $30 \mathrm{G}$ needle in different directions very slowly and placed in a refrigerator at $5^{\circ} \mathrm{C}$ for $1 \mathrm{~h}$. After $1 \mathrm{~h}$, the same medium, $2 \mathrm{ml}$ each, were inoculated again to each cauda epididymis in the same treated groups and placed at $5^{\circ} \mathrm{C}$ again for another $1 \mathrm{~h}$ for equilibration. Two hrs after equilibration, all the testes along with treated epididymides $(n=60)$ were wrapped properly with aluminium foils to prevent the deposition of ice-crystals directly on the testes and 
epididymal surfaces and stored immediately into refrigerator at $-10^{\circ} \mathrm{C}$ without an automatic defrosting cycle. The specimens were placed in a way that the entire testicular along with epididymal surfaces remained beneath 3 inch from the upper floor, 3 inch above from the lower floor and 6 inch apart from both the side walls of the refrigerator ice-box so that each testis remained in the ice vapour properly. The control epididymides along with testes $(n=20$ without any treatment) were also equilibrated and stored in similar ways.

\section{Thawing procedure}

Thawing of the epididymides along with testes including the controls ( $n=10$ from each group) were performed after 7 and 21 days of freezing respectively. Before thawing aluminium foil were removed from the testes and epididymides and were allowed to warm to room temperature $(35 \pm$ $2{ }^{\circ} \mathrm{C}$ ) for $2 \mathrm{~min}$ and immersed immediately into a water bath at $38.5 \pm 1{ }^{\circ} \mathrm{C}$ for $5 \mathrm{~min}$ till the outer surface of the testes as well as epididymides were softened.

Post-thaw evaluation of cauda epididymal spermatozoa

Thawed cauda epididymides were dissected carefully from both the ligated ends of vasdeferens and corpus epididymides. Each cauda was kept into separate Petridishes containing $5 \mathrm{ml}$ of $0.15 \mathrm{M}$ phosphate buffer saline (PBS) $\mathrm{p}^{\mathrm{H}} 7.4$, previously warmed to $37^{\circ} \mathrm{C}$. Caudal portions were minced carefully with razor blades and were allowed to suspend in the buffer for $5 \mathrm{~min}$ at $37^{\circ} \mathrm{C}$. Gentle pressure on the excised tissues was given by separate glass rods. Each resultant suspension was filtered through nitex membrane $(150 \mu)$ to free the cellular debris. Filtrates were collected separately into individual sterile coded centrifuge tubes, centrifuged twice at $500 \mathrm{~g}$ for $10 \mathrm{~min}$ and the supernatants were discarded each time. All the sperm pellets were resuspended again with $2 \mathrm{ml}$ of $\mathrm{PBS}$, vortexed gently for $3 \mathrm{~s}$ and placed into an incubator at $37^{\circ} \mathrm{C}$ for $10 \mathrm{~min}$ containing $5 \% \mathrm{CO}_{2}$ in air. After incubation, $10 \mu \mathrm{l}$ of sperm suspension from each test tube was transferred to other coded sterile glass test tubes and $190 \mu \mathrm{l}$ of PBS was added to each sperm suspension and incubated as above for $5 \mathrm{~min}$ for subsequent evaluations.

Assessment of spermatozoan progressive motility

Spermatozoan progressive motility from different treated groups including controls were evaluated [23] under Leitz phase contrast microscope $(\times 100, \times 200$; Germany). An arbitrary scale (kinetic rating) of a " 0 to 5 " was used to determine the spermatozoan progressive motility by scoring 200 individual sperm cells from each sample in triplicate and their mean results were expressed in percent motile.
Assessment of spermatozoan viability

Live spermatozoa from treated and control epididymides were evaluated by Eosin-Nigrosin stain [24]. Two hundred sperm cells were counted randomly at least from 10 different microscopic fields under the light microscope $(\times 200 ; \times 400)$. The mean results from 3 individual stained slides from each caudal portion were counted and their mean results were expressed in percent viable spermatozoa.

Assessment of spermatozoal plasmamembrane integrity

Hypo-osmotic swelling (HOS) test of thawed cauda epididymal spermatozoa from both the control and EF media treated groups were performed with 150 mOsm HOS solution [25]. A total of 200 sperm cells from 10 different microscopic fields were counted randomly under Leitz phase contrast microscope $(\times 200 ; \times 400)$. Sperm cells that exhibited different types of tail coiling were scored thrice from 3 slides of each individual sample and the mean values were expressed as percent HOS positive sperm.

Statistical analysis

All the data were analyzed by general linear model by SPSS-10 [26]. The multiple means were compared using Duncan Multiple Range (DMR) Test.

\section{Results}

Table 1 depict that EF media treated in-vivo epididymal spermatozoan characters were diminished gradually and significantly $(P<0.001 ; P<0.05)$ at 21 days when compared with freeze-thawed epididymal spermatozoa at 7 days.

Spermatozoan progressive motility (\%) was completely absent in control specimens but highest progression remained in SLCoQ10G followed by CoQ10G and SLG media respectively. Effect of the media on the spermatozoan progressive motility after day 7 revealed significant variations $(P<0.001)$ among the media, however, at 21 days it did not vary between the SLG and CoQ10G medium but both varied significantly $(P<0.001)$ with SLCoQ10G medium respectively.

Maximum viable sperm cells (\%) were remained in SLCoQ10G followed by CoQ10G and SLG treated medium and in control specimens. Viable sperm cells recovered respectively after 7 and 21 days of post-thawing exhibited significant variations $(P<0.001)$ among the media including controls, except between SLG and CoQ10G treated sperm cells.

Percentage of HOS positive (coiled tailed) spermatozoa observed after 7 and 21 days of post-thawing also revealed 
Table 1 Spermatozoan Motility, Viability and HOS positivity of post-thaw in situ caudal spermatozoa (\%) treated with EF media and freezed at $-10{ }^{\circ} \mathrm{C}$ for 7 and 21 days

\begin{tabular}{|c|c|c|c|c|c|c|}
\hline Parameter studied & \multicolumn{2}{|l|}{ Motility } & \multicolumn{2}{|c|}{ Live Spermatozoa } & \multicolumn{2}{|c|}{ HOS Positive Spermatozoa } \\
\hline Treatment & 7 & 21 & 7 & 21 & 7 & 21 \\
\hline Control EF media & $0^{\mathrm{a}}$ & $0^{\mathrm{a}}$ & $10.5 \pm 0.83^{\mathrm{ae}}$ & $6.0 \pm 0.12^{\text {af }}$ & $5.2 \pm 0.14^{\mathrm{ae}}$ & $4.1 \pm 0.35^{\mathrm{ae}}$ \\
\hline SLG & $29.9 \pm 0.69^{\text {be }}$ & $23.5 \pm 0.75^{\text {be }}$ & $41.9 \pm 0.90^{\text {be }}$ & $37.4 \pm 0.85^{\text {be }}$ & $37.9 \pm 0.56^{\mathrm{bf}}$ & $33.5 \pm 0.73^{b f}$ \\
\hline CoQ10G & $31.5 \pm 0.84^{\mathrm{ce}}$ & $25.5 \pm 1.12^{\text {be }}$ & $43.1 \pm 0.65^{\text {be }}$ & $39.4 \pm 0.76^{\text {be }}$ & $39.2 \pm 0.91^{\text {be }}$ & $35.4 \pm 1.03^{\text {be }}$ \\
\hline SLCoQ10G & $35.5 \pm 0.93^{\mathrm{de}}$ & $30.2 \pm 0.62^{\text {ce }}$ & $50.6 \pm 0.93^{\mathrm{ce}}$ & $45.2 \pm 0.82^{\mathrm{ce}}$ & $45.7 \pm 0.95^{\mathrm{cf}}$ & $41.6 \pm 0.79^{\mathrm{cf}}$ \\
\hline$P$ value & $<0.001$ & $<0.001$ & $<0.001$ & $<0.001$ & $<0.001$ & $<0.001$ \\
\hline
\end{tabular}

$n=10$ for each treatment and days of observation. Values expressed as mean $\pm \mathrm{SE}$

Different superscripts $(a, b, c, d)$ row wise differ significantly at $1 \%$ level ${ }^{\mathrm{e}}$ differ significantly at $1 \%$ level (coloum wise) ${ }^{\mathrm{f}}$ differ significantly at $5 \%$ level (coloum wise)

SLCoQ10G medium provided higher protection to sperm plasmamembrane (SPM) than any other media including controls. It was also observed that number $(\%)$ of coiled tailed spermatozoa in controls varied significantly $(P<$ $0.001)$ from the EF media treated groups, but between SLG and CoQ10G medium, treated spermatozoa did not vary, however, both varied $(p<0.001)$ with the SLCoQ10G treated spermatozoa.

\section{Discussion}

Recovery of spermatozoa at postmortem and its successful preservation is important to save the valuable gene pool which requires successive experimentations. It is well known that epididymal sperm particularly caudal sperm though mature but are most sensitive to freeze-thawing than all the germ cells examined including ejaculated sperm. This is due to maximum decrease in the concentration of phospholipids in caudal spermatozoa during maturation phases of spermatozoa [27-29]. Therefore, prediction for effectiveness of any media and its components are very important during cold preservation/freezing of sperm cells, particularly spermatozoa from cauda epididymal region. In this experimental model, in-vivo caprine cauda epididymal spermatozoa treated with EF media and freezed at critical temperature of $-10^{\circ} \mathrm{C}$ were able to withstand cold shock effectively and was found to be better than preservation at $4-5^{\circ} \mathrm{C}[9,10]$. Though gradually diminished, treated spermatozoa maintained good progressive motility, viability and plasmamembrane integrity after freezing till up to 21 days of observation. The protective effectiveness of EF media on the sperm cells during freeze thawing varied with their compositions. Synergestic effect(s) of SL and CoQ10 provided best protection to the freezed-thawed spermatozoa against cold shock (Table 1).

It is revealed from the present experiment that spermatozoan characteristics though diminished can be restored successfully within the epididymides with EF media at $10^{\circ} \mathrm{C}$ for considerable long days where SL as membrane stabilizing agent and CoQ10 both as membrane stabilizing agent and antioxidant acted very well.

Protection offered to spermatozoa by SL during Freezethaw cycle, may be due to its lipid components interacting with specific membrane proteins of spermatozoa, or may cause a more general shift in membrane fluidity that supports membrane-dependant actions. SL contains phospholipids. Soyaphosphatidylecholine contributes to the structural integrity of the cells by protecting fatty acids from damage caused by Reactive Oxygen Species (ROS) and by lowering lipid peroxidation (LPO) to the cell membrane and thus stabilize SPM [30].

CoQ10 exhibits both antioxidative and membrane stabilizing property and helps to prevent sperm cells from damage caused by ROS and other free radicals [31]. Testicular tissues and sperm viability are particularly vulnerable to peroxidative injury produced by free radical. ROS is responsible to increase the LPO of SPM and leads to its damage causing infertility [32]. CoQ10 encourages better sperm motility and viability by providing protections against the damaging effects of ROS and by preventing LPO in SPM thus maintained SPM integrity [33]. CoQ10 is an essential component in the synthesis of ATP in the cells and is concentrated in the mitochondria of the sperm midpiece, as well as an integral redox and proton translocating component of the mitochondrial respiratory chain [34], so that the energy for movement and all other energydependant processes in the sperm cells are also dependant on the availability of CoQ10 [35]. Importantly, CoQ10 helps to regenerate the oxidized vitamin $\mathrm{E}$ thus converting it into strong antioxidant and helps to recycle and preserve vitamin $\mathrm{E}$ thus prevents its prooxydant activity which helps in energy production in the sperm cells $[36,37]$. As CoQ10 is highly lipophilic, it could reasonably hypothesized that this antioxidant can diffuse the phospholipid bilayer of cellular membrane and thus protect the SPM. Moreover, 
carrier substances present in the cell membrane can transport glucose under the influence of CoQ10, and by this mechanism in the presence of added CoQ10, probably more glucose are able to reach inside the cell where intracellular metabolic machinery took over it for energy metabolism and thus sperm become more capable to withstand the rigors of freezing and thawing better [38]. Exogenous administration of CoQ10 has been found to ameliorate the results of membrane integrity test [39] which possibly simulate with the present finding.

Though EF media are able to protect the caudal spermatozoa from freeze damage, however, were unable to protect the gametes as functional not more than $45 \%$ after freeze-thawing. Moreover, it has been observed that increasing freezing time had detrimental effects also on the EF media treated sperm cells (Table 1). We consider nine possible reasons for the diminishing characteristics of treated sperm cells.

(i) Though the addition of cryoprotective agents (CPA) are essential for sperm survival following freezing process, but can cause loss in sperm viability due to osmotic damage or from true chemical toxicity. The addition of CPA before freezing and their removal after warming creates an anistonic environment resulting in potentially damaging osmotically driven cell volume changes. Such changes in solution osmolality (Solution effect) and in cell volume can be responsible for loss in the functional integrity of sperm [40]. Glycerol can affect physical features in the cytoplasm, permeability and stability of the membrane bilayer and metabolism on noncovalent attachment of proteins to the sperm surface [41]. But, the biochemical mechanisms of these type of toxicity are unknown. However, prolong storage of sperm with glycerol is ultimately detrimental to the sperm cells, because sperm cells metabolically convert glycerol into a toxic metabolite known as "methyglyoxal" [42], which might be an important factor associated with the variations in freezability of sperm [43].

(ii) During freeze-thaw cycle, a substantial portion of the sperm cells undergo irreversible damage due to thermal, mechanical, chemical and osmotic stress $[44,45]$. There occurs significant differentiation in sperm biophysical characters, such as cell surface area, cell volume, water volume and membrane permeability to water [46]. The sperm plasma membrane is of crucial importance to freeze-thaw survival of spermatozoa and is regarded as primary site of freezing injury. Ice-crystal mediated damage of SPM affects spermatozoan motility and viability seriously and is responsible to be a major cause of cell death due to freezing. A large portion of cell destruction has also been observed when the transition period from the liquid to solid phase or vice-versa is prolonged [47]. Moreover, slow freezing at $-10^{\circ} \mathrm{C}$ is also detrimental to spermatozoa due to the formation of more crystals inside the cell and in the immediate environment of the cells which is responsible to pears the SPM.

(iii) Plasma membrane disruption due to cooling and freezing also favours the loss of cations and enzymes from the sperm cells [48] and destroy the selective permeability of SPM to calcium leading to excessive intracellular level of this ion which reduce the spermatozoan motility and lead to necrosis to the sperm cells $[49,50]$.

(iv) LPO and subsequent membrane damage are at its peak during the thawing process due to free radicals toxic oxygen metabolites that are produce at low levels in the cells with a restricted supply of oxygen, concomitantly, there is an increase in free radicals production on restoration of $\mathrm{O}_{2}$ supply to the cells. It is speculated that this sudden increase in $\mathrm{O}_{2}$ utilization by sperm cells during thawing following the dormant metabolic stage, might be responsible for increased production of free radicals, leading to increase in LPO which is a causal factor for spermatozoan membrane damage [51].

(v) Two main sites of ROS production are in mitochondria and in SPM. During freezing of sperm cells, there is production of ROS [40,52] causes change in membrane functions and structure of the cells which induce alteration in antioxidant defense system of the cells [52]. The SPM serves as the main physical barrier to the outside environment and is a primary site of freeze-thaw damage. Such damage includes membrane destabilization due to lateral lipid rearrangement [53-55], loss of lipid from the membrane [56], and peroxidation of membrane lipids as a result of formation of ROS [32, 57, 58]. These events can affect spermatozoan motility and response to osmotic stress as well as alters the signaling pathways of the cells. Cold shock damage is directly linked to lipid phase transitions leading SPM to become transiently leaky, and thus affect the cellular membrane integrity [59].

(vi) The decrease in spermatozoan characteristics in different treatment groups and between the days could have been a result from individual variations in the sperm quality. Heterogeneous sperm populations are found in the cauda epididymis i.e. completely mature, nearly maturing and aged sperm cells remain in the cauda epididymis. Being in a differentiated state, compared to other cells, may explain their resistance to cold shock. 
(vii) Excess generation of ROS from dead / defective sperm cells, $[54,60]$ and leukocytes $[61,62]$ might be another causal factor that initiates detrimental effects to the normal sperm cells.

(viii) EF media when inoculated into the cauda epididymides plausibly, the solutions were not able to enter evenly into all the epididymal tubular loops to reach to the sperm cells properly for their protection resulting more cellular death.

(ix) Another causal factor for diminishing freeze-thawed sperm characteristics might be the thawing procedure which requires further study.

The freezing protocols are simple, novel, and more effective than preservation of whole epididymis at 4 to $5^{\circ} \mathrm{C}$ and can be performed easily in the field condition. Laboratories that do not have very good facilities may follow this protocol until they are ready to send the specimens to distant laboratories for immediate processing. Hence, to prevent a substantial loss and to maximize the utilization of valuable genotypes this method would definitely meaningful one towards genetic conservation and improvement of diminishing animal species. However, future research in this aspect needs to be developed.

\section{References}

1. Foote RH. Letter to the Editor. J. Androl. 2000;21(3):355.

2. Anel L, Guerra C, Alvarez M, Kaabi M, Anel E, Boixo JC, et al. Basic parameters in spermatozoa recovered post-mortem from the Spanish Cantabrian Chamois (Rupicapra pyrenaica parva). Theriogenology. 2000;53(1):323. abstract.

3. Blash S, Melican D, Gavin W. Cryopreservation of epididymal sperm obtained at necropsy from goats. Theriogenology. 2000;54 (6):899-905.

4. Kilian I, Lubbe K, Bartels P, Friedmann Y, Denniston RS. Evaluating epididymal sperm of African wild ruminants: Longevity when stored at $4^{\circ} \mathrm{C}$ and viability following cryopreservation. Theriogenology. 2000;53(1):330. abstract.

5. Lubbe K, Bartels P, Kilian I, Friedmann Y, Godke RA. Comparing motility and morphology of horse, zebra and rhinoceros epididymal spermatozoa when cryopreserved with two different cryodiluents or stored at $4^{\circ} \mathrm{C}$. Theriogenology. 2000;53(1):338. abstract.

6. Soler AJ, Perez-guzman MD, Grade J. Storage of red deer epididymides for four days at $5^{\circ} \mathrm{C}$ : effects on motility, viability and morphological integrity. J. Exp. Zool. Part A: Comparative Exp. Biol. 2003;295A:188-99.

7. Martinez-Pastor F, Guerra C, Kabbi M, Diaz AR, Anel E, Herraez $\mathrm{P}$, et al. Decay of sperm obtained from epididymis of wild ruminants depending on postmortem time. Theriogenology. 2005;63(1):24-40.

8. Dong Q, Rodenberg SE, Huang C, Vandevoort CA. Cryopreservation of Rhesus monkey (Macaca muitatta) epididymal spermatozoa before and after refrigerated storage. J. Androl. 2008;29(3):283-92.

9. James AN, Green H, Hoffman S, Landry AM, Paccamonti D, Godke RA. Preservation of equine sperm stored in the epididymides at $4^{\circ} \mathrm{C}$ for $24,48,72$ and 96 Hours. Theriogenology. 2002;58:401-4.
10. Yu I, Leibo SP. Recovery of motile, membrane-intact spermatozoa from canine epididymides stored for 8 days at $4^{\circ} \mathrm{C}$. Theriogenology. 2002;57:1179-90.

11. Fournier-Delpech S, Colas G, Courot M, Ortavant R, Brice G. Epididymal sperm maturation in the ram: motility, fertilizing ability and embryonic survival after uterine artificial insemination. Ann. Biol. Anim. Bioch. Biophys. 1979;19(3A):597-605.

12. Niwa K, Ohara K, Hosoi Y, Iritani A. Early events of in-vitro fertilization of cat eggs by epididymal spermatozoa. J. Reprod. Fertil. 1985;74(2):657-60.

13. Temple-Smith PD, Southwick GJ, Yates CA, Trounson AO, de Kretser DM. Human pregnancy by in vitro fertilization (IVF) using sperm aspirated from the epididymis. J. In Vitro Fertil. Embryo Transfer. 1985;2:119-222.

14. Marks SL, Dupuis J, Mickelsen WD, Memon MA, Platz CC. Conception by use of postmortem epididymal semen extraction in a dog. J. Anim. Vet. Med. Assoc. 1994;204(10):1639-40.

15. Graff KJ, Chandler JE, Reggio BC, Lim JM, Canal A, Carter JA, Meintjes M, Godke RA: Pregnancies obtained from IVF with noncapacitated epididymal bovine spermatozoa. Proc. 3rd Intern'l. Mtg. Biotech. Anim. Reprod. Cairo, Egypt (Nov. 2-6). 1996: pp. 19-21.

16. Bonduel M, Wilikens A, Buysse A, Van Assche E, Devroey P, Van Steirteghem AC, et al. A follow-up study of children born after intracytoplasmic sperm injection (ICSI) with epididymal and testicular spermatozoa and after replacement of cryopreserved embryos obtained after ICSI. Hum. Reprod. 1998;13(Suppl 1): 196-207.

17. Morrell JM, Nubbemeyer R, Heistermann M, Rosenbusch J, Kuderling I, Holt W, et al. Artificial insemination in Callithrix jacchus using fresh or cryopreserved sperm. Anim. Reprod. Sci. 1998;52(2):165-74.

18. Bartels P, Lubbe K, Kilian I, Friedmann Y, van Dyk G, Mortimer D. In vitro maturation and fertilization of lion (Panthera leo) oocytes using frozen-thawed epididymal spermatozoa recovered by cauda epididymectomy of an immobilized lion. Theriogenology. 2000;53(1):325. abstract.

19. Kusunoki H, Daimaru H, Miami S, Nishimoto S, Yamane K-I, Fukumoto Y. Birth of a chimpanzee (Pan troglodytes) after artificial insemination with cryopreserved epididymal spermatozoa collected postmortem. Zoo. Biol. 2001;20:135-43.

20. Ikeda H, Kikuchi K, Noguchi J, Takeda H, Shimada A, Mizokami $\mathrm{T}$, et al. Effect of preincubation of cryopreserved porcine epididymal sperm. Theriogenology. 2002;57:1309-18.

21. Martins CF, Rumpf R, Pereira DC, Dode MN. Cryopreservation of epididymal bovine spermatozoa from dead animals and its use in in-vitro embryo production. Anim. Reprod. Sci. 2007;101:32631.

22. Said S, dan Saili T. Rescuing genetic material of unexpectedly die animal. Jurnal Ilmu Ternak dan Veteriner. 2007;12(2):147-52.

23. World health Organization: WHO Laboratory manual for the examinations of human semen and sperm-cervical mucus interaction (3e). Cambridge; The press syndicated of the University of Cambridge. 1997.

24. Sidhu KS, Guraya SS: In: Buffalo bull semen morphology, biochemistry, physiology and methodology. USA publishers and distributors, Ludhiana, India. 1985a; 152-154.

25. Jeyendran RS, Vandervent HH, Perez-Paleac ZM, Crabo BG, Zaneveld LJD. Development of an assay to assess the functional integrity of human sperm membrane and its relationship to other semen characteristics. J. Reprod. Fertil. 1984;70:219-25.

26. Duncan DB. Multiple range and multiple F tests. Biometrics. 1955;11:1-42.

27. Scott TW, Voglmayer JK, Setchell BP. Lipid composition and metabolism in testicular and ejaculated spermatozoa. The Biochemical Journal. 1967;102:456-60. 
28. Arora R, Dinakar N, Prasad MRN. Biochemical changes in the spermatozoa and luminal contents of different regions of the epididymis of the rhesus monkey, Macaca mulalta. Contraception. 1975;11:689-700.

29. Hammerstedt RH, Keith AD, Hay S, Deluca N, Amann RP. Changes in ram sperm membrane during epididymis transit. Arch. Biochem. Biophys. 1979;196:7-12.

30. Thun R, Hurtado M, Janett F. Comparison of Biociphos-plus and TRIS-egg yolk extender for cryopreservation of bull semen. Theriogenology. 2002;57:1087-94.

31. Mancini A, Marinis LD, Oradei A, Hallgass ME, Conte G, Pozza $\mathrm{D}$, et al. Coenzyme Q10 concentration in normal and pathological Human seminal fluid's. J. Androl. 1994;15(6):591-4.

32. Jones R, Mann T. Damage to ram spermatozoa by peroxidation of endogenous phospholipids. J.Reprod. Fertil. 1977;50:261-8.

33. Ernster L, Forsneark-Andree P. Ubiquinol: an endogenous antioxidant in aerobic organisms. Clin. Invest. 1993;71:S60-65.

34. Ernster L, Dallner G. Biochemical, physiological and medical aspects of ubiquinone function. Biochem. Biophys. Acta. 1995;1271:195-204.

35. Lewin A, Lavon H. The effect of Coenzyme Q10 on sperm motility and function. Molecular Aspects of Medicine. 1997;18 (Suppl):S 213-9.

36. Thomas SR, Neuzil J, Stocker R. Co supplementation with coenzyme Q prevents the prooxidant effects of alphatocopherol and increase the resistance of LDL to transition metal-dependent oxidation initiation. Arterioscler. Thromb. Vasc. Biol. 1996;16: 687-96.

37. Thomas SR, Neuzil J, Stocker R. Inhibition of LDL oxidation by ubiquinone-10. A protective mechanism for coenzyme $\mathrm{Q}$ in atherogenesis? Mol.Aspects. Med. 1997;18:S85-103.

38. Booth NH, McDonald LE. Veterinary pharmacology and Therapeutics. 6th ed. New Delhi: Kalyani publisher; 1982.

39. Mazzilli F, Cerasaro M, Bisanti A, Rossi T, Dondero F: Seminal parameters and the swelling test in patients with sperm before and after treatment with ubiquinone (CoQ10). $2^{\text {nd }}$ international symposium on reproductive medicine. Acta Medica, Edizioni e Congresi, Rome, Italy: Fiuggi. 1988; 71.

40. Ball BA, Vo AT, Baumber J. Reactive oxygen species generation by equine spermatozoa. Am. J. Vet. Res. 2001;62:5508-15.

41. Hammerstedt RH, Graham JK, Nolan JP. Cryopreservation of mammalian sperm: What we ask them to survive. J. Androl. 1990;11:73-88.

42. Riddle VM, Lorenz N. Nonenzymic formulation of toxic levels of methylglyoxal from glycerol and dihydroxyacetone in Ringers phosphate suspensions of avian spermatozoa. Biochem, Biophy. Res. Commun. 1973;50:27-34.

43. Fahy GM, Lilley TH, Linsdell H, Douglas MS, Meryman HT. Cryoprotectant toxicity and cryoprotectant toxicity reduction: In search of molecular mechanisms. Cryobiol. 1990;27:247-68.

44. Watson PF. The effects of cold shock on sperm cell membranes. In: Morris GJ, Clark A, editors. Effects of Low temperatures on Biological membranes. London: Academic; 1981. p. 189-218.
45. Rodojcic L, Vukotic-Maletic V, Balint B. Current Knowledge on cryopreservation of spermattzoa, ovum cells and zygotes. Medicinski pregled. 1998;51(1-2):29-36.

46. Curry MR, Watson PF. Osmotic effects on ram and human sperm membranes in relation to thawing injury. Cryobiology. 1994;31 (1):39-46.

47. Watson PF. Recent developments and concepts in the cryopreservation of spermatozoa and the assessment of their post-thawing function. Reprod. Fertility. Dev. 1995;7:747-869.

48. Harrison RAP, White IG. Glycolytic enzymes in the spermatozoa and cytoplasmic droplets of bull, boar and ram and their leakage after shock. J Reprod Fertil. 1972;30:105-15.

49. Simpson AM, White IG. Effect of cold shock and cooling rate on calcium uptake of ram spermatozoa. Anim. Reprod. Sci. 1986;12:131-43.

50. Robertson L, Bailey JL, Buhr MM. Effects of cold shock and phospholipase A2 on intact boar spermatozoa and sperm head plasma membranes. Mol. Reprod Dev. 1990;26:143-9.

51. Cotran RS, Kumar V, Robbins SL. Robbin's Pathologic basis of disease. 4th ed. Philadelphia: WB Saunders Co; 1989. p. 9-16.

52. Bilodeau JF, Chatterjee S, Sired MA, Gagnon C. Levels of antioxidant defenses are decreased in bovine spermatozoa after a cycle of freezing and thawing. Mol. Reprod. Dev. 2000;55:282-8.

53. Quinn PJ. Principles of membrane stability and phase behavior under extreme conditions. J Bioenerg Biomembr. 1989;21:3-19.

54. Holt WV, North RD. The role of membrane - active lipids in the protection of ram spermatozoa during cooling and storage. Gamete Res. 1988;19:77-89.

55. De Leeuw FE, Chen HC, Colenbrander B, Verkleji AJ. Coldinduced ultra structural changes in bull and boar sperm plasma membranes. Cryobiology. 1990;27:171-83.

56. Buhr MM, Curtis EF, Kakuda NS. Composition and behavior of head membrane lipids of fresh and cryopreserved boar sperm. Cryobiology. 1994;31:224-38.

57. White IG. Lipids and calcium uptake of sperm in relation to cold shock and preservation: A review. Reproduction. Fertility. Dev. 1993;5(6):639-58.

58. Aitken RJ. Free radicals, lipid peroxidation and sperm function. Reprod. Fertil. Dev. 1995;7:659-68.

59. Drobinis EZ, Crowe LM, Berger T, Anchordoguy TJ, Overstreet JW, Crowe JH. Cold shock damage is due to lipid phase transitions in cell-membranes-a demonstration using sperm as a model. J. Exp. Zool. 1993;265:432-7.

60. Rao B, Soufir JC, Martin M. Lipid peroxidation in human spermatozoa as related to mid piece abnormalities and motility. Gamete Res. 1989;24:127-34.

61. Aitken RJ, West K, Buckingham DW. Leukocytic infiltration into the human ejaculate and its association with semen quality, oxidative stress, and sperm function. J. Androl. 1994;15:343-52.

62. Baumber J, Ball BA, Gravance CG, Medina V, Davies-Morel MC. The effect of reactive species on equine sperm motility, viability, acrosomal integrity, mitochondria membrane potential, and membrane lipid peroxidation. J.Androl. 2001;21:895-902. 